\title{
Cost-effective routes for catalytic biomass upgrading
}

\author{
W. Jin ${ }^{1}$, L. Pastor-Pérez ${ }^{1}$, Jie $\mathrm{Yu}^{2}$, J. A. Odriozola ${ }^{1,3}$, \\ S. $\mathrm{Gu}^{1}$ and T. R. Reina ${ }^{1}$
}

\begin{abstract}
Catalytic hydrodeoxygenation (HDO) is a fundamental and promising route for bio-oil upgrading to produce petroleum-like hydrocarbon fuels or chemical building blocks. One of the main challenges of this technology is the demand of high-pressure $\mathrm{H}_{2}$, which poses high costs and safety concerns. Accordingly, developing cost-effective routes for biomass or bio-oil upgrading without the supply of commercial $\mathrm{H}_{2}$ is essential to implement the HDO at commercial scale. This article critically reviewed the very recent studies relating to the novel strategies for upgrading the biofeedstocks with 'green' $\mathrm{H}_{2}$ generated from renewable sources. More precisely, catalytic transfer hydrogenation/hydrogenolysis, combined reforming and HDO, combined metal hydrolysis and HDO, water-assisted in-situ HDO and nonthermal plasma technology and self-supported hydrogenolysis are reviewed herein. Current challenges and research trends of each strategy are also proposed aiming to motivate further improvement of these novel routes to become competitive alternatives to conventional HDO technology.
\end{abstract}

\begin{abstract}
Addresses
${ }^{1}$ Department of Chemical and Process Engineering Department, University of Surrey, Guildford, GU2 7XH United Kingdom

${ }^{2}$ State Key Laboratory of Coal Combustion, Huazhong University of Science and Technology, Wuhan, China

${ }^{3}$ Departamento de Química Inorgánica e Instituto de Ciencia de Materiales de Sevilla, Avda. Americo Vespucio 49, 41092 Sevilla, Spain
\end{abstract}

Corresponding author: Reina, T.R (t.ramirezreina@surrey.ac.uk)

Current Opinion in Green and Sustainable Chemistry 2020, 23:1-9

This review comes from a themed issue on Green processes and technologies

Edited by Xiangping Zhang

Available online 08 January 2020

https://doi.org/10.1016/j.cogsc.2019.12.008

2452-2236/○ 2020 Elsevier B.V. All rights reserved.

\section{Introduction}

The increasing energy demand and environmental pollution arise the use of sustainable and low-carbon energy to decrease the excessive dependence on limited fossil fuels. In the recent decades, biomass has sparked great interest becoming one among renewable sources considering its distinctive features, such as low price, low-carbon emission, abundant storage and wide distribution [1]. Among all technologies, depolymerization and deoxygenation are two essential processes for biomass valorisation to produce highvalued chemicals and transportation fuels. Hydrodeoxygenation (HDO) technology is typically applied for bio-oil upgrading in which the oxygen will be removed in the form of water. Previous study about the HDO of biofeedstocks mainly focused on bio-oil model compounds to obtain fundamental mechanistic understanding of bio-oil upgrading process. Recently, the upgrading of crude bio-oil has gained more attention. The 'Achilles Heel' of this technology is demand of high pressure $\mathrm{H}_{2}-$ an expensive resource which could impose security consideration and an economic barrier for its application on commercial scale [2]. Recently, novel strategies are being developed for bio-oil or biomass upgrading with in situ generated hydrogen thus suppressing external $\mathrm{H}_{2}$ supply. These novel routes include (1) catalytic transfer hydrogenation/hydrogenolysis (CTH), (2) combined reforming and HDO (RHDO) process, (3) combined metal hydrolysis and HDO process, (4) water-assisted in situ HDO process, (5) nonthermal plasma (NTP) and (6) self-supported hydrogenolysis (SSH). The hydrogen source of each technology was depicted in Figure 1. Catalytic HDO of bio-oil have been extensively reviewed by $\mathrm{Li}$ [3], Besson [4] and Kim et al. [5]. Herein, the most recent findings regarding six cost-effective routes for bio-oil or biomass upgrading were selectively overviewed in this work (Figure 1), facilitating the design of advanced catalysts and motivating the development of potentially economically viable route for catalytic biomass or bio-oil upgrading.

\section{Catalytic transfer hydrogenation/ hydrogenolysis}

Apart from the in situ $\mathrm{H}_{2}$ generation, the CTH technology owns several advantages such as mild reaction conditions, high atom efficiency and less cost of the experimental setup [6]. Moreover, it is demonstrated that CTH strategy can avoid the excessive hydrogenation and thus favour the production of aromatic hydrocarbons compared with conventional HDO route $[7,8]$. The CTH technology is still in the bud for its application in the HDO of bio-oils, especially for phenolic compounds [8]. The challenge of this strategy remains on the enhancement of deoxygenation rates.

The rational design of catalysts for facilitating synchronous $\mathrm{H}_{2}$ generation and selective $\mathrm{C}-\mathrm{O}$ bond cleavage of biofeedstocks is the key to fulfilling the high HDO 


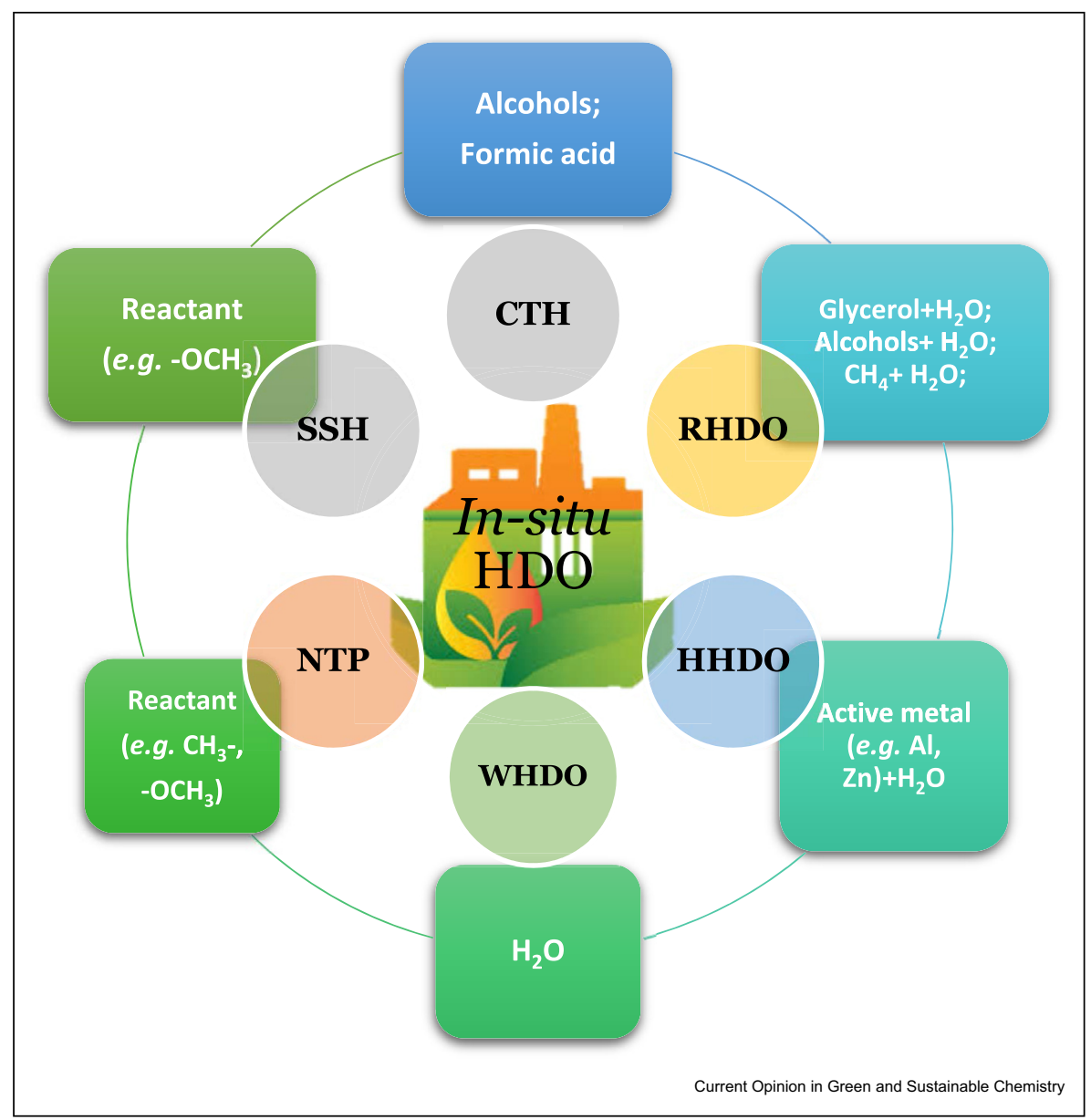

Novel strategies for bio-oil or biomass HDO with in situ hydrogen generation. CTH, catalytic transfer hydrogenation/hydrogenolysis; RHDO, combined reforming with hydrodeoxygenation; HHDO, combined metal hydrolysis with hydrodeoxygenation; WHDO, water-assisted in situ hydrodeoxygenation; NTP, nonthermal plasma; SSH, self-supported hydrogenolysis; HDO, hydrodeoxygenation.

efficiency. In most existing investigations, noble catalysts including $\mathrm{Ru}, \mathrm{Pd}$ and $\mathrm{Pt}$ and non-noble catalysts including $\mathrm{Ni}$ and Co are among the best candidates for CTH of phenolic compounds. Typically, bimetallic catalysts are superior to monometallic catalyst because of the introduction of a suitable second metal tuning the metal-H strength on the metal surface, which significantly impacts the decomposition of $\mathrm{H}$-donor and $\mathrm{H}_{2}$ spillover rates. The optimization of metal-H bonding strength is still a challenge. Most recently, Jin et al. [6] hypothesised the atom $\mathrm{H}$ transfer route for monometallic, bimetallic admixture showcasing the potential of bimetallic catalysts in CTH process. For bimetallic catalyst, the CTH reactions involved the atomic $\mathrm{H}$ transfer from one metal site to another, whereas the dehydrogenation of hydrogen donor and the hydrogenolysis are proposed to occur on the same metal site for alloyed bimetallic catalysts [6]. For RANEY Ni catalytic system with 2-proponal as hydrogen donor, the reactivity patterns vary with the position of methoxy group on the substrate. The ATR-IR spectra revealed that the adsorbed guaiacol assumes a parallel orientation to the catalyst surface, which allows a strong interaction between the methoxy $\mathrm{C}-\mathrm{O}$ bond and the surface of catalyst. Conversely, the adsorption of 3- or 4methoxyphenol leads to a tilted surface complex in which the methoxy $\mathrm{C}-\mathrm{O}$ bond establishes no interaction with the catalyst [9].

Formic acid [10,11] and alcohols (e.g. methanol [12], ethanol [13,14], 2-proponal [15-17]), have been proved efficient hydrogen donor for CTH process. Generally speaking, small molecules, such as methanol and formic acid are more selective to $\mathrm{H}_{2}$ generation compared with long chain alcohols. The deteriorated properties for $\mathrm{H}_{2}$ production could be attributed to the high extent of parallel consumption routes in the upgrading process (i.e. dehydration, condensation and 
etherification) [18]. More recently, researchers are making effort on applying the CTH idea in upgrading of raw feedstocks. $\mathrm{Mg}-\mathrm{Ni}-\mathrm{Mo}$ catalyst supported by $\mathrm{KOH}$ treated activated charcoal was demonstrated to be effective for upgrading the biotar with supercritical ethanol as the H-donor [14]. The oxygen content decreased from $30.5 \mathrm{wt} . \%$ to $11.7 \mathrm{wt} . \%$ through series of reactions, such as esterification, hydrogenation, deoxygenation and ring alkylation. Similarly, methanol was proved to be effective hydrogen donor for the upgrading of pyrolytic oil (degree of deoxygenation $=50-$ $54 \%$ ) over $\mathrm{Pd} / \mathrm{C}$ and $\mathrm{Pt} / \mathrm{C}$ catalyst [19]. Further improvement on enhancing the stability of catalyst is needed, considering the obvious deactivation of catalyst caused by the carbon deposition. Recently, the group of McClelland [12] investigated the supercritical methanol depolymerization and hydrogenation (SCMDHDO) of maple wood and two extracted lignins over reduced porous copper metal oxides using supercritical methanol as hydrogen source. The effective HDO reflects on the decreased $\mathrm{O} / \mathrm{C}$ ratio of feedstock SCMDHDO products, in which the $\mathrm{O} / \mathrm{C}$ ratio decreased from 0.32 in gamma-Valerolactone (GVL) extracted lignin to 0.06 and 0.04 in GVL extracted lignin and maple wood products derived through SCM-DHDO process at $300^{\circ} \mathrm{C}$. Similarly, Regmi et al. [13] investigated the CTH of organosolv lignin over B-containing $\mathrm{FeNi}$ alloyed catalysts using supercritical ethanol as the hydrogen donor at $320^{\circ} \mathrm{C}$. It is demonstrated that the $\mathrm{B}$-containing $\mathrm{FeNi}$ alloys could mediate the selective CTH of ketones to alkanes. The addition of $\mathrm{B}$ as hpromoter could enhance the hydrogenation of $\mathrm{C}=\mathrm{O}$ bond and $\mathrm{C}-\mathrm{O}$ hydrogenolysis. By using acetophenone as a model compound in this process, high reactivity
$($ Conversion $=74 \%)$ and selectivity towards completed deoxygenated product, ethylbenzene (Selectivity $=$ 84\%) was obtained. Surprisingly, the addition of external $\mathrm{H}_{2}$ in the catalytic system decreased the monophenols production for the CTH of lignin over $\mathrm{PtRe} / \mathrm{TiO}_{2}$ with 2-propanol as hydrogen source. The competitive adsorption of active sites on catalysts might result in the adverse effect of $\mathrm{H}_{2}$ on the depolymerization of lignin [17]. Generally, the combination of depolymerization and CTH in one pot simplified the experimental setup and is effective for the lignin monomers production.

\section{Combined reforming and HDO process}

The RHDO strategy resembles to the CTH strategy discussed in the previous section. Some authors classify the RHDO route to the CTH for liquid phase in situ $\mathrm{HDO}$ process probably due to reforming of $\mathrm{H}$-donor (e.g. alcohols) might happen with the participation of $\mathrm{H}_{2} \mathrm{O}$ produced from the hydrogenolysis process. In this review, the route of RHDO is emphasised because the concept of RHDO route is designed with reforming as the main $\mathrm{H}_{2}$ generation route instead of the decomposition or dehydrogenation of $\mathrm{H}$-donor. Figure 2 depicts a scheme of the in situ HDO via CTH and RHDO route.

Fernando et al. [20] proposed the strategy for bio-oil deoxygenation using in situ hydrogen generated from methane steam reforming. In this process, the multiple reactions including biomass oxygenates dehydration and aromatization together with the methane steam reforming make it realizable for upgrading the bio-oil into aromatic hydrocarbons. Further improvement relating to the deoxygenation degree is urgently needed;

\section{Figure 2}

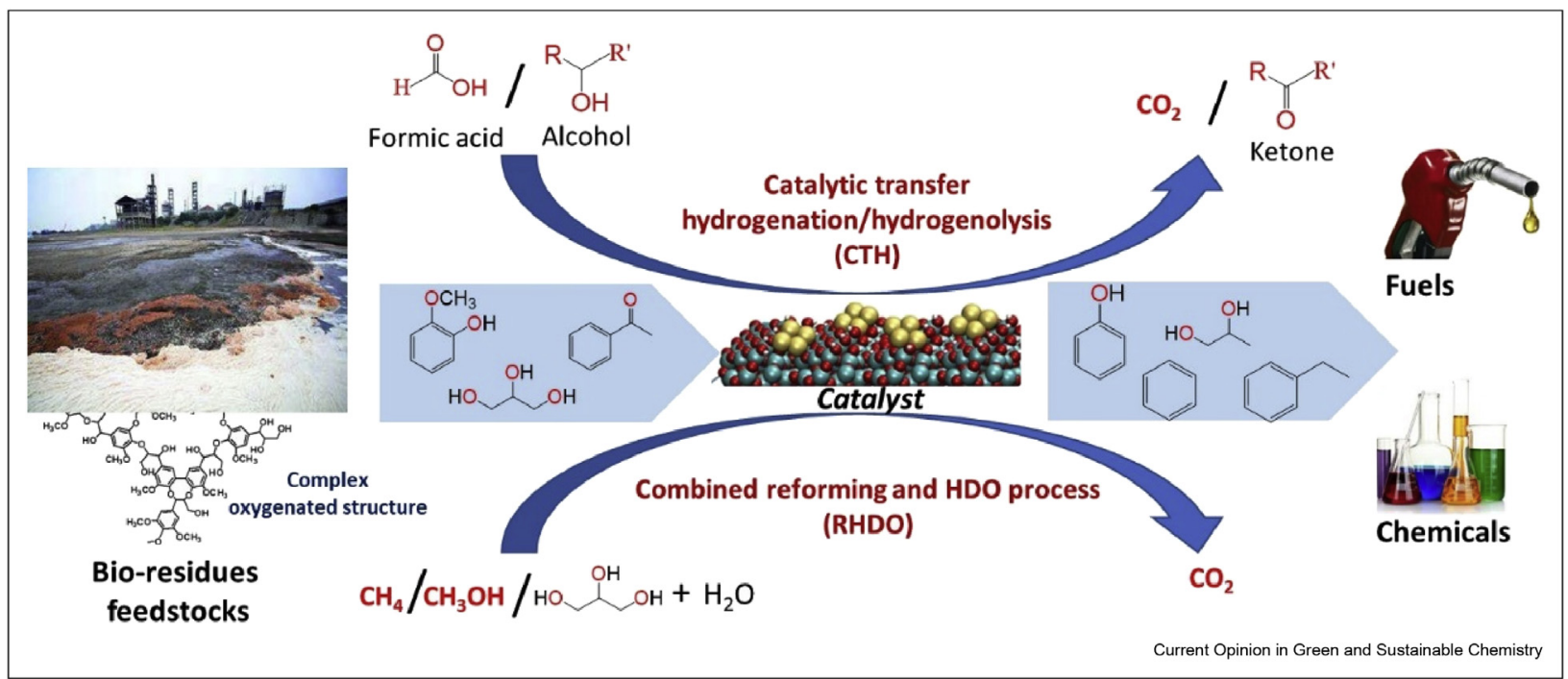

Catalytic biomass upgrading via $\mathrm{CTH}$ and RHDO routes. HDO, hydrodeoxygenation; $\mathrm{CTH}$, catalytic transfer hydrogenation/hydrogenolysis; $\mathrm{RHDO}$, combined reforming and HDO. 
however, no new publications for bio-oil upgrading via this route is observed in the recent years.

$\mathrm{H}_{2}$ formation rate for methanol reforming is higher than the dehydrogenation of other common hydrogen donors (including formic acid, ethylene glycol, ethanol, 1-propanol, 2-propanol, 1-butanol, 2-butanol and tertbutanol) in catalytic systems with the absence of biofeedstocks. Moreover, methanol is proved to be the best H-donor for selective production of 1,2propanediol from glycerol [18]. Glycerol is the one of the main by-products during the biodiesel production. $\mathrm{H}_{2}$ production from the sacrifice of part of substrates can upgrade the glycerol to deoxygenated products [21,22]. More recently, attempts about using glycerol aqueous phase reforming (APR) as the hydrogen source for the bio-oil upgrading process were conducted by researchers. Remón et al. [23] proposed using crude glycerol as the hydrogen source for the valorisation of bio-oil in supercritical water. Results indicated that the synergistic interaction between crude glycerol and biooil results in an important decrease in the solid yield [23]. Domínguez-Barroso et al. [24] combined of glycerol-APR and the HDO of fatty acid over PtNi/ $\mathrm{Al}_{2} \mathrm{O}_{3}$ catalysts. However, low deoxygenation conversion of fatty acid (37\%) was obtained considering the difference between the optimal condition of glycerolAPR $\left(200^{\circ} \mathrm{C}\right)$ and in situ HDO of fatty acid $\left(275^{\circ} \mathrm{C}\right)$. Overall, the RHDO route is promising for the nonfossil $\mathrm{H}_{2}$-based HDO process. The matching of APR and HDO condition should be the key consideration for the design of catalytic upgrading system.

\section{Combined metal hydrolysis and HDO process}

Active metals, such as beryllium (Be), aluminium (Al), zinc $(\mathrm{Zn})$, magnesium $(\mathrm{Mg})$, Calcium $(\mathrm{Ca})$, lithium

Figure 3

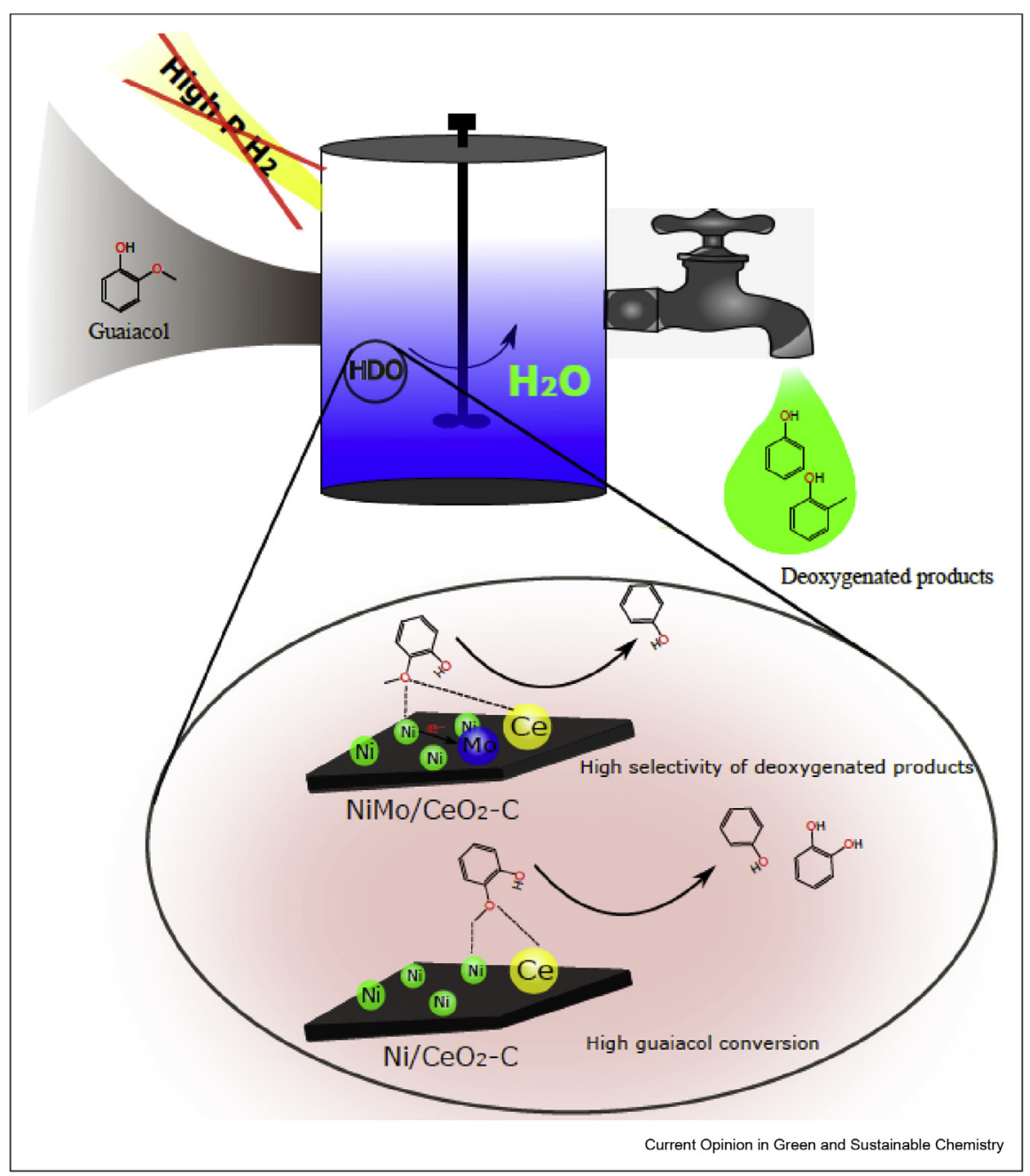

$\mathrm{HDO}$ of guaiacol over Ni-based catalyst using water as the H-donor (reprinted from a study by Jin et al. [32]. Copyright $2019 \mathrm{Wiley-VCH} \mathrm{Verlag} \mathrm{GmbH} \mathrm{\&}$ Co. KGaA, Weinheim). HDO, hydrodeoxygenation. 


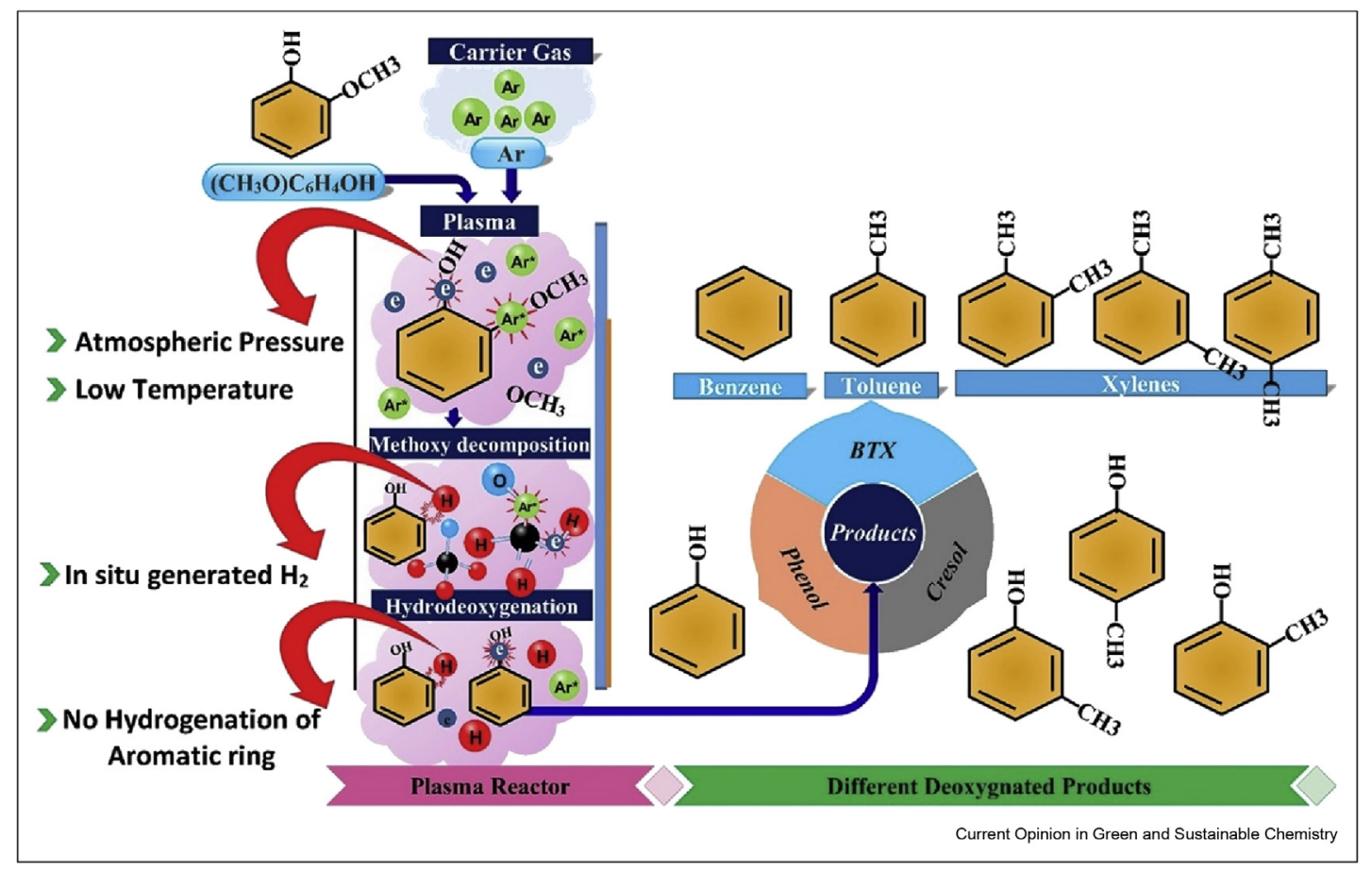

HDO of guaiacol using NTP technology conducted in DBD plasma reactor reproduced from a study by Taghvaei et al. [39]. HDO, hydrodeoxygenation; NTP, nonthermal plasma; DBD, dielectric barrier discharge.

(Li), sodium $(\mathrm{Na})$, and potassium $(\mathrm{K})$ can produce $\mathrm{H}_{2}$ by reacting with water. $\mathrm{Zn}$ and $\mathrm{Al}$ excellent candidates. Combined metal hydrolysis and HDO process (HHDO) owns several advantages compared with other novel routes. For example, HDO is favoured because the energy can be released from the exothermal metal hydrolysis process. Besides, metallic oxide, such as $\mathrm{ZnO}$, $\mathrm{AlOOH}$ and $\mathrm{MgO}$ has catalytic properties [25], which might promote the HDO reaction.

Cheng et al. [26] first proposed the in situ HDO of biooil with hydrogen generated from zinc hydrolysis. However, the deoxygenation degree is not satisfactory, in which oxygen content decreased from $48.78 \%$ wt.\% to 30.20 wt.\% over $\mathrm{Pd} / \mathrm{C}$ at $250{ }^{\circ} \mathrm{C}$ [27]. They further investigated the catalytic liquefaction of pine sawdust and in situ hydrogenation of biocrude over $\mathrm{Co}-\mathrm{Zn} /$ HZSM-5 catalysts by using zinc hydrolysis as the hydrogen source. The bimetallic Co-Zo/HZSM-5 is superior to monometallic Co/HZSM-5 and Zn/HZSM-5 in terms of the production of hydrocarbons considering the synergistic effect of Co and $\mathrm{Zn}$ on the support. The oxygen content decreased significantly from original $44.87 \mathrm{wt} . \%$ in pine sawdust to $15.29 \mathrm{wt} . \%$ for upgraded bio-oil [28]. After the same strategy, zero-valent aluminium ( $\mathrm{ZV}-\mathrm{Al})$ and bio-oil aqueous phase were used as hydrogen source in Yang's study [29]. As a result, the degree of deoxygenation of crude bio-oil reached
76.38\%. The higher hydrogen yield derived from the reaction of $\mathrm{ZV}-\mathrm{Al}$ and bio-oil aqueous phase compared with that of $\mathrm{ZV}$-AL and water can be attributed to the aqueous phase reforming reactions in the catalytic reaction system. In summary, HHDO is effective for deoxygenation of biofeedstocks. However, the cost of $\mathrm{H}_{2}$ production from $\mathrm{Zn}$ and $\mathrm{Al}$ mental hydrolysis is higher than the industrial $\mathrm{H}_{2}$ and the recovery of zerovalent metal is the main challenge for the commercial application of HHDO strategy. Cheng et al. [26] proposed a looped-Zn catalysis for metal recycle and bio-oil HDO process, in which the metallic oxide produced from the metal hydrolysis can be recycled by using solar energy. However, the implementation of this concept requires massive investment on the instruments for chemical industry.

\section{Water-assisted in situ HDO process}

Water is the greenest solvent overall [30] and has the potential to provide hydrogen in HDO process. However, very limited attempts have been made in the HDO by using water as hydrogen source. Water-assisted in situ HDO process (WHDO) route is quite challenging due to the limitations imposed by water splitting. Jin et al. [31] proposed for the first time this new route for the in situ HDO using water as the hydrogen source. They investigated the HDO of guaiacol in water-only reaction 
system using noble metal ( $\mathrm{Au}, \mathrm{Pd}, \mathrm{Ru}$ and $\mathrm{Rh})$ [31] and non-noble metal (Ni) [32] as catalysts. They achieved remarkable conversion of guaiacol using $\mathrm{Ru} / \mathrm{C}$ and no external $\mathrm{H}_{2}$ supply indicating that water is likely to be the main hydrogen donor in this process [31]. However, the reactant can also supply $\mathrm{H}_{2}$ in this reaction. According to the study of Zhang et al., [33] the monoaromatic such as phenol and catechol might be produced from the isomerization of guaiacol, the cracking of the side chains and the rearrangement of the functionalities of the guaiacol. Miyagawa et al. [34] investigated the demethoxylation of hydrogenated derivatives of guaiacol in water-only reaction system. Methanol could be formed from hydrolysis reaction of the reactant. In contrast to Jin's study, the hydrogen applied for the HDO process is generated from the dehydrogenation of cyclohexane and methanol reforming.

The proposed WHDO opens a new way for the biomass upgrading process. However, more investigations relating to the $\mathrm{H}$-transfer route are needed to solidify this new concept. The understanding of the WHDO

\begin{tabular}{|c|c|c|c|c|}
\hline Upgrading strategy & Hydrogen source/mechanism & $\begin{array}{l}\text { Typical operation } \\
\text { parameters }\end{array}$ & Pros & Cons \\
\hline Conversional HDO & $\mathrm{H}_{2}$ & $\begin{array}{l}200-400{ }^{\circ} \mathrm{C} \\
40-200 \text { bar }\end{array}$ & $\begin{array}{l}\text { High } \\
\text { deoxygenation } \\
\text { efficiency }\end{array}$ & $\begin{array}{l}\text { High cost of } \mathrm{H}_{2} \text {; safety concern such as } \mathrm{H}_{2} \\
\text { transportation and storage; } \\
\text { side reactions: hydrogenation of aromatic rings }\end{array}$ \\
\hline $\begin{array}{l}\text { Catalytic transfer } \\
\text { hydrogenation/ } \\
\text { hydrogenolysis } \\
\text { (CTH) }\end{array}$ & $\begin{array}{l}\text { Decomposition or } \\
\text { dehydrogenation of H-donors } \\
\text { (e.g. alcohols, formic acid) }\end{array}$ & $\begin{array}{l}\text { Room } \\
\text { temperature-300 } \\
{ }^{\circ} \mathrm{C} \\
\text { Atmospheric } \\
\text { pressure } \\
-120 \text { bar }\end{array}$ & $\begin{array}{l}\text { Mild reaction } \\
\text { condition; } \\
\text { Low cost of } \\
\text { renewable H- } \\
\text { donor; } \\
\text { Reduced } \\
\text { complexity and } \\
\text { cost of the } \\
\text { experiment set-up; } \\
\text { Comparable } \\
\text { deoxygenation } \\
\text { efficiency }\end{array}$ & $\begin{array}{l}\mathrm{CO}_{2} \text { production; By-product separation; Low } \\
\text { stability of catalysts because of the acidic } \\
\text { reaction environment (i.e. formic acid as } \mathrm{H}- \\
\text { donor) }\end{array}$ \\
\hline $\begin{array}{l}\text { Combined } \\
\text { reforming and } \\
\text { HDO process } \\
\text { (RHDO) }\end{array}$ & $\begin{array}{l}\text { Steam reforming or aqueous } \\
\text { phase reforming of } \mathrm{H} \text {-donors (e.g. } \\
\text { alcohols, methane and glycerol) }\end{array}$ & $\begin{array}{l}200-400{ }^{\circ} \mathrm{C} \\
5-200 \text { bar }\end{array}$ & $\begin{array}{l}\text { Low cost of } \\
\text { renewable H- } \\
\text { donor; } \\
\text { Comparable } \\
\text { deoxygenation } \\
\text { efficiency } \\
\text { Reduced } \\
\text { complexity and } \\
\text { cost of the } \\
\text { experiment setup }\end{array}$ & $\begin{array}{l}\mathrm{CO}_{2} \text { production; } \\
\text { Low stability of catalysts due to the acidic } \\
\text { reaction environment (i.e. formic acid as } \mathrm{H} \text { - } \\
\text { donor) }\end{array}$ \\
\hline $\begin{array}{l}\text { Combined Metal } \\
\text { Hydrolysis and } \\
\text { HDO Process } \\
\text { (HHDO) }\end{array}$ & $\begin{array}{l}\text { Hydrolysis of active metal (e.g. Al, } \\
\text { Zn). }\end{array}$ & $\begin{array}{l}250-400^{\circ} \mathrm{C} \\
50-300 \text { bar }\end{array}$ & $\begin{array}{l}\text { Comparable } \\
\text { deoxygenation } \\
\text { efficiency }\end{array}$ & $\begin{array}{l}\text { High energy input in terms of the recovery of } \\
\text { active metal }\end{array}$ \\
\hline $\begin{array}{l}\text { Water-assisted in- } \\
\text { situ HDO } \\
\text { Process } \\
\text { (WHDO) }\end{array}$ & $\begin{array}{l}\text { Water splitting or hydrogen } \\
\text { transfer }\end{array}$ & $\begin{array}{l}200-300^{\circ} \mathrm{C} \\
50-100 \text { bar }\end{array}$ & $\begin{array}{l}\text { Low cost and } \\
\text { abundance of } \\
\text { water; } \\
\text { reduced } \\
\text { complexity and } \\
\text { cost of the } \\
\text { experiment set-up }\end{array}$ & Relatively low deoxygenation ability \\
\hline $\begin{array}{l}\text { Nonthermal } \\
\text { plasma (NTP) }\end{array}$ & $\begin{array}{l}\text { Hydrogen radicals produced from } \\
\text { cracking of methyl group in } \\
\text { reactant }\end{array}$ & $\begin{array}{l}\text { Room } \\
\text { temperature; } \\
\text { atmospheric } \\
\text { pressure }\end{array}$ & $\begin{array}{l}\text { Mild reaction } \\
\text { condition; } \\
\text { alleviated catalyst } \\
\text { deactivation }\end{array}$ & High cost of experimental setup \\
\hline $\begin{array}{l}\text { Self-supported } \\
\text { hydrogenolysis } \\
\text { (SSH) }\end{array}$ & $\begin{array}{l}\text { Hydrogen production from } \\
\text { methoxy group in the reactant }\end{array}$ & $\begin{array}{l}175-300^{\circ} \mathrm{C} \\
5 \text { bar }\end{array}$ & $\begin{array}{l}\text { High } \\
\text { deoxygenation } \\
\text { efficiency; } \\
\text { no external H- } \\
\text { donor needed. }\end{array}$ & $\begin{array}{l}\mathrm{CO}_{2} \text { production; reactant restricted to aromatic } \\
\text { ethers }\end{array}$ \\
\hline
\end{tabular}

HDO, hydrodeoxygenation. 
mechanism could inspire the catalysis community to develop effective catalysts for this economically appealing route (See Figure 3).

\section{Nonthermal plasma}

Taghvaei et al. [35] first proposed the in situ HDO of biooil through NTP technology. The cracking methyl group in the structure of biofeedstocks could provide hydrogen radicals which is required for HDO reactions. The coaxial cylinder dielectric barrier discharge plasma reactor is typically used in bio-oil upgrading process. The investigations of NTP for bio-oil upgrading mainly focus on the optimizing of operation and plasma parameters and the catalyst formula.

Taghvaei et al. [36] did intensive investigations about the HDO of anisole, 4-methylanisole [37], guaiacol [38] with in situ hydrogen generation through NTP technology. More recently, they applied the NTP to the upgrading of guaiacol over different $\mathrm{Al}_{2} \mathrm{O}_{3}$ supported catalyst [39]. Unlike the previous studies in which catechol was the major products, this catalytic system produced high selectivity of aromatic hydrocarbons and phenols. High guaiacol conversion (92\%) and deoxygenation degree (65\%) were obtained using $\mathrm{Pt}-\mathrm{Cl} / \mathrm{Al}_{2} \mathrm{O}_{3}$ and $\mathrm{Pt}-\mathrm{Re} / \mathrm{Al}_{2} \mathrm{O}_{3}$ as catalysts, respectively. Fan et al. [40] compared the onestep and two-step plasma-catalytic upgrading of biooil to biofuel over different HZSM-5 supported catalysts by using dielectric barrier discharge plasma reactor. They found that one-step configuration is superior to two-step configuration. The proportion of desired hydrocarbon products reached $68.89 \%$ in the bio-oil upgrading process over Ti/HZSM-5 catalyst. Considering the mild reaction condition (ambient temperature and pressure), which could alleviate the catalyst coking, NTP has gained much more attention in the recent few years. Recent progress on the enhancement of the HDO degree makes the NTP technology a comparable approach compared with CTH and WHDO. However, more research about the upgrading of raw bio-oil using NTP is still an open question (See Figure 4).

\section{Self-supported hydrogenolysis strategy}

Very recently, Meng et al. [41] proposed a new strategy, called self-supported hydrogenolysis (), for converting aromatic ethers to arenes without exogenous $\mathrm{H}_{2}$ and other additional H-donors. The selectivity of an aromatic ether could reach $>99.9 \%$ at full conversion of the reactant over $\mathrm{RuW} / \mathrm{SiO}_{2}$ bimetallic catalyst. The results of isotope labelling test indicated that the $\mathrm{H}$ source in the $\mathrm{SSH}$ route is from aliphatic $\mathrm{H}$ in methoxy group on the reactant rather than the water solvent. The strategy of SSH opens a novel way for the deoxygenation of aromatic ethers to produce arenes without the supply of external $\mathrm{H}_{2}$ or $\mathrm{H}$-donor solvent.
The typical operation parameters and features of conversional HDO and novel in situ HDO strategies were summarized in Table 1.

\section{Conclusions and perspectives}

This review critically discussed the novel routes for bio-oil and biomass upgrading to produce value-added chemicals and hydrocarbon oils. Overall, the in situ HDO using CTH and RHDO gains more attention of catalysis community considering relatively sound theoretical basis of these technologies. In contrast, NTP is quite promising even though the investigation of its application in the biomass upgrading field is still in the bud. However, it has the potential to upgrade bio-oil in a noncatalytic process. Finding an economic way for the recycling of zero-valent metal is the main challenge for the hop of HHDO to realworld application. It is worth emphasizing that the most challenging route, WHDO, would pose tremendous impact on biorefinery industry if it is successfully proved. The SSH strategy can avoid the addition of $\mathrm{H}$-donor and it is quite promising because of the high deoxygenation efficiency. Overall, the future of biocompounds upgrading will be linked to these novel approaches, where inexpensive, highly effective catalysts and a green solvent are used opening new opportunities in the field of low-carbon technologies. Nevertheless, the application of these novel technologies in raw biomass feedstocks still needs further exploration.

\section{Conflict of interest statement}

Nothing declared.

\section{Acknowledgements}

Financial support in the UK for this work was provided by the Department of Chemical and Process Engineering of the University of Surrey and the EPSRC grants EP/J020184/2 and EP/R512904/1, as well as the Royal Society Research Grant RSGR1180353. W.J. thanks the Chinese Scholarship Council (CSC) and LPP also thanks Comunitat Valenciana for her postdoctoral fellow (APOSTD2017).

\section{Appendix A. Supplementary data}

Supplementary data to this article can be found online at https://doi.org/10.1016/j.cogsc.2019.12.008.

\section{References}

Papers of particular interest, published within the period of review, have been highlighted as:

* of special interest

* of outstanding interest

1. Hu L, Lin L, Wu Z, Zhou S, Liu S: Recent advances in catalytic transformation of biomass-derived 5-hydroxymethylfurfural into the innovative fuels and chemicals. Renew Sustain Energy Rev 2017, 74:230-257.

2. Jin W, Pastor-Pérez L, Shen D, Sepúlveda-Escribano A, Gu S, Ramirez Reina T: Catalytic upgrading of biomass model compounds: novel approaches and lessons learnt from traditional hydrodeoxygenation-a review. ChemCatChem 2019, 11:924-960. 
3. Li C, Zhao X, Wang A, Huber GW, Zhang T: Catalytic transformation of lignin for the production of chemicals and fuels. Chem Rev 2015, 115:11559-11624.

4. Besson Ml, Gallezot P, Pinel C: Conversion of biomass into chemicals over metal catalysts. Chem Rev 2013, 114: 1827-1870.

5. Kim S, Kwon EE, Kim YT, Jung S, Kim HJ, Huber GW, Lee J: Recent advances in hydrodeoxygenation of biomass-derived oxygenates over heterogeneous catalysts. Green Chem 2019, 21:3715-3743.

6. Jin X, Yin B, Xia Q, Fang T, Shen J, Kuang L, Yang C: Catalytic transfer hydrogenation of biomass-derived substrates to value-added chemicals on dual-function catalysts: opportunities and challenges. ChemSusChem 2019, 12:71-92.

This review discussed recent studies about the catalytic transfer hydrodegation technology for biomass upgrading and pointed out the opportunities and challenges in this field. It also proposed the $\mathrm{H}$ transfer route for bimetallic and alloy catalyst in CTH process.

7. Guo T, Xia Q, Shao Y, Liu X, Wang Y: Direct deoxygenation of lignin model compounds into aromatic hydrocarbons through hydrogen transfer reaction. Appl Catal Gen 2017, 547: $30-36$.

8. Gilkey MJ, Xu B: Heterogeneous catalytic transfer hydrogenation as an effective pathway in biomass upgrading. ACS Catal 2016, 6:1420-1436.

9. de Castro IBD, Graça I, Rodríguez-García L, Kennema M, Rinaldi R, Meemken F: Elucidating the reactivity of methoxyphenol positional isomers towards hydrogen-transfer reactions by ATR-IR spectroscopy of the liquid-solid interface of RANEY@ Ni. Catal Sci Technol 2018, 8: 3107-3114.

10. Hidajat MJ, Riaz A, Kim J: A two-step approach for producing oxygen-free aromatics from lignin using formic acid as a hydrogen source. Chem Eng J 2018, 348:799-810.

11. Verma S, Nadagouda MN, Varma RS: Visible light-mediated and water-assisted selective hydrodeoxygenation of ligninderived guaiacol to cyclohexanol. Green Chem 2019, 21: $1253-1257$.

12. McClelland DJ, Galebach PH, Motagamwala AH, Wittrig AM, Karlen SD, Buchanan JS, Dumesic JA, Huber GW: Supercritical methanol depolymerization and hydrodeoxygenation of lignin and biomass over reduced copper porous metal oxides. Green Chem 2019, 21:2988-3005.

13. Regmi YN, Mann JK, McBride JR, Tao J, Barnes CE, Labbé N, Chmely SC: Catalytic transfer hydrogenolysis of organosolv lignin using B-containing FeNi alloyed catalysts. Catal Today 2018, 302:190-195.

14. Lee J-H, Lee I-G, Park J-Y, Lee K-Y: In-situ upgrading of bio-tar over Mg-Ni-Mo catalyst supported by $\mathrm{KOH}$ treated activated charcoal in supercritical ethanol. Fuel 2019, 247:334-343.

15. Kim M, Ha J-M, Lee K-Y, Jae J: Catalytic transfer hydrogenation/hydrogenolysis of quaiacol to cyclohexane over bimetallic RuRe/C catalysts. Catal Commun 2016, 86:113-118.

16. Philippov A, Chibiryaev A, Martyanov O: Raney® nickelcatalyzed hydrodeoxygenation and dearomatization under transfer hydrogenation conditions-reaction pathways of non-phenolic compounds. Catal Today 2019. https://doi.org/ 10.1016/j.cattod.2019.05.033.

17. Hu J, Zhang S, Xiao R, Jiang X, Wang Y, Sun Y, Lu P: Catalytic transfer hydrogenolysis of lignin into monophenols over platinum-rhenium supported on titanium dioxide using isopropanol as in situ hydrogen source. Bioresour Technol 2019, 279:228-233.

18. Yfanti V-L, Lemonidou A: Effect of hydrogen donor on glycerol hydrodeoxygenation to 1, 2-propanediol. Catalysis Today; 2019. https://doi.org/10.1016/j.cattod.2019.04.080.

In this study, the hydrogen production ablility of common hydrogen donor and their performance in glycerol hydrodeoxygenation were extensively investigated.
19. Mohammed IY, Abakr YA, Mokaya R: Catalytic upgrading of pyrolytic oil via in-situ hydrodeoxygenation. Waste and Biomass Valorization; 2019:1-13.

20. Fernando S, Gunawardena DA: Deoxygenation of biomass derived oxygenates to hydrocarbons via direct methane intervention. Google Patents; 2017.

21. Liu S, Tamura M, Shen Z, Zhang Y, Nakagawa $Y$, Tomishige K: Hydrogenolysis of glycerol with in-situ produced $\mathrm{H} 2$ by aqueous-phase reforming of glycerol using Pt-modified Ir-ReOx/SiO2 catalyst. Catal Today 2018, 303: $106-116$.

22. Freitas IC, Manfro RL, Souza MM: Hydrogenolysis of glycerol to propylene glycol in continuous system without hydrogen addition over Cu-Ni catalysts. Appl Catal B Environ 2018, 220 $31-41$.

23. Remón J, Arcelus-Arrillaga P, García L, Arauzo J: Simultaneous production of gaseous and liquid biofuels from the synergetic co-valorisation of bio-oil and crude glycerol in supercritical water. Appl Energy 2018, 228:2275-2287.

24. Domínguez-Barroso V, Herrera C, Larrubia MÁ, Alemany LJ: Coupling of glycerol-APR and in situ hydrodeoxygenation o fatty acid to produce hydrocarbons. Fuel Process Technol 2019, 190:21-28.

25. Ogale SB, Venkatesan TV, Blamire M: Functional metal oxides: new science and novel applications. John Wiley \& Sons; 2013.

26. Cheng S, Wei L, Julson J, Muthukumarappan K, Kharel PR, Cao Y, Boakye E, Raynie D, Gu Z: Hydrodeoxygenation upgrading of pine sawdust bio-oil using zinc metal with zero valency. J Taiwan Inst Chem Eng 2017, 74:146-153.

27. Cheng S, Wei L, Alsowij MR, Corbin F, Julson J, Boakye E, Raynie D: In situ hydrodeoxygenation upgrading of pine sawdust bio-oil to hydrocarbon biofuel using $\mathrm{Pd} / \mathrm{C}$ catalyst. J Energy Inst 2018, 91:163-171.

28. Cheng S, Wei L, Rabnawaz M: Catalytic liquefaction of pine sawdust and in-situ hydrogenation of bio-crude over bifunctional Co-Zn/HZSM-5 catalysts. Fuel 2018, 223: $252-260$.

This paper first investigated the catalytic liquefaction of biomass and bio-oil upgarding over non-noble catalyst using metal hydrolysis as hydrogen source.

29. Yang T, Shi L, Li R, Li B, Kai X: Hydrodeoxygenation of crude bio-oil in situ in the bio-oil aqueous phase with addition of zero-valent aluminum. Fuel Process Technol 2019, 184 $65-72$.

30. Zhou F, Hearne Z, Li C-J: Water-the greenest solvent overall. Curr Opin Green Sustain Chem 2019, 18:118-123.

31. Jin W, Santos JL, Pastor-Perez L, Gu S, Centeno MA, Reina TR: * * Noble metal supported on activated carbon for "hydrogen free" HDO reactions: exploring economically advantageous routes for biomass valorisation. ChemCatChem; 2019. https://doi.org/ $10.1002 /$ cctc. 201900841.

This is the first study to combine water splitting and hydrodeoxygenation of bio-oil model compounds.

32. Jin W, Pastor-Perez L, Villora-Picó JJ, Sepúlveda-Escribano A, Gu S, Reina T: Investigating new routes for biomass upgrading "H2-free" hydrodeoxygenation using Ni-based catalysts. ACS Sustainable Chemistry \& Engineering; 2019. https://doi.org/ 10.1021/acssuschemeng.9b02712.

33. Zhang Z, Hu X, Zhang L, Yang Y, Li Q, Fan H, Liu Q, Wei T, Li C$\mathrm{Z}$ : Steam reforming of guaiacol over Ni/Al2O3 and Ni/SBA-15: impacts of support on catalytic behaviors of nickel and properties of coke. Fuel Process Technol 2019, 191:138-151.

34. Miyagawa A, Nakagawa Y, Tamura M, Tomishige K: Demethoxylation of hydrogenated derivatives of guaiacol without external hydrogen over platinum catalyst. Molecul Catal 2019, 471:60-70.

35. Taghvaei $\mathrm{H}$, Kheirollahivash $\mathrm{M}$, Ghasemi M, Rostami $\mathrm{P}$ Gates BC, Rahimpour MR: Upgrading of anisole in a dielectric barrier discharge plasma reactor. Energy Fuel 2014, 28: $4545-4553$. 
36. Taghvaei $\mathrm{H}$, Kheirollahivash $\mathrm{M}$, Ghasemi M, Rostami $\mathrm{P}$, Rahimpour MR: Noncatalytic upgrading of anisole in an atmospheric DBD plasma reactor: effect of carrier gas type, voltage, and frequency. Energy Fuel 2014, 28: 2535-2543.

37. Mosallanejad A, Taghvaei H, Mirsoleimani-azizi SM, Mohammadi A, Rahimpour MR: Plasma upgrading of 4methylanisole: a novel approach for hydrodeoxygenation of bio oi without using a hydrogen source. Chem Eng Res Des 2017, 121:113-124.

38. Taghvaei $\mathrm{H}$, Rahimpour MR: Plasma upgrading of guaiacol as lignin pyrolytic-oil model compound through a combination of hydrogen production and hydrodeoxygenation reaction. J Anal Appl Pyrolysis 2018, 135:422-430.

39. Taghvaei H, Rahimpour MR: Catalytic hydrodeoxygenation of bio-oil using in situ generated hydrogen in plasma reactor: effects of allumina supported catalysts and plasma parameters. Process Saf Environ Prot 2019, 121: $221-228$.

40. Fan Y, Xiong Y, Zhu L, Fan L, Jin L, Chen Y, Zhao W: Comparison of the one-step and two-step plasma-catalytic upgrading of biomass pyrolysis volatiles to bio-fuel. Chem Eng Proc Insenificat 2019, 135:53-62.

This study compared the one-step and two step bio-oil upgrading via plasma technology. High yield of hydrocarbon products was obtained in one-step configuration.

41. Meng QL, Yan J, Liu HZ, Chen CJ, Li SP, Shen XJ, Song JL, ** Zheng LR, Han BX: Self-supported hydrogenolysis of aromatic ethers to arenes. Sci Adv 2019, 5, eaax6839.

This study first proposed the SSH stratagy to convert aromatic ethers to arenes. High deoxygenation efficience of reactant was achieved without the supply of $\mathrm{H}_{2}$ and $\mathrm{H}$-donor solvent. 